\title{
CONSIDERAÇÕES ACERCA DA INTERPRETAÇÃO E PRIMEIRAS IDEIAS SOBRE UMA TEORIA DA DECISÃO
}

\author{
http://dx.doi.org/10.21527/2176-6622.2020.53.141-152
}

Recebido em: 26/3/2019

Aceito em: 21/6/2019

Fernando de Brito Alves

Doutor em Direito pelo Centro Universitário de Bauru. Estágio Pós-Doutorado no Ius Gentium Conimbrigae. Graduado em filosofia (USC) e Direito (Uenp). Mestre em Ciência Jurídica pela Uenp. Coordenador do Programa de Mestrado e Doutorado da Universidade Estadual do Norte do Paraná (2018-2022). http://lattes.cnpq.br/1975997868167667. https://orcid.org/0000-0001-8917-4717. alvesfb@uol.com.br

Vinicius Scherch

Mestre em Ciência Jurídica na Universidade Estadual do Norte do Paraná (Uenp). Especialista em Direito Constitucional Contemporâneo pelo Instituto de Direito Constitucional e Cidadania (IDCC). Especialista em Direito e Processo do Trabalho pela Universidade do Norte do Paraná (Unopar). Especialista em Administração Pública pelo Centro Universitário de Maringá Unicesumar. Graduado em Direito pela Faculdade Cristo Rei (Faccrei). http://lattes.cnpq.br/1721329870636878. https://orcid.org/0000-0003-3671-3822. vinnyscherch@hotmail.com

\section{RESUMO}

Este artigo tem como objeto a interpretação constitucional. Aborda a questão do Direito e a interpretação das regras no contexto da discricionariedade judicial. Leva em conta a criação de um método racional e coerente para a formatação de decisões, especialmente em casos difíceis. Como resultado é possível, a partir dos textos de Hesse, Dworkin, Moreso e Bulygin, compreender como a discricionariedade deve estar no sentido fraco, abaixo da Constituição, considerando as propriedades mais importantes e possibilitando a criação do Direito a partir de noções preexistentes. A metodologia de pesquisa utilizada foi bibliográfica e deu-se pelo método hipotético-dedutivo. A conclusão é que a teoria da decisão é necessária compreendendo a discricionariedade como uma atividade criativa, porém com a atribuição de racionalidade, coerência com critérios legais e respeito aos aspectos históricos e sociais.

Palavras-chave: Discrição judicial. Interpretação racional. Teoria da decisão.

CONSIDERATIONS ABOUT INTERPRETATION AND FIRST IDEAS ON A DECISION THEORY

\section{ABSTRACT}

This article has as its object the constitutional interpretation. It addresses the issue of law and the interpretation of rules in the context of judicial discretionarity. It takes into account the creation of a rational and coherent method for formatting decisions, especially in hard cases. As a result, it is possible, from the texts of Hesse, Dworkin, Moreso and Bulygin, to understand how discretions should be in the narrow sense, below the Constitution, considering the most important properties and enabling the creation of the right from preexisting notions. The research methodology used was bibliographic and the hypothetical deductive method was used. The conclusion is that decision theory is necessary to understand discretionaty as a creative activity, but with the attribution of rationality, coherency with legal criteria and respect for historical and social aspects.

Keywords: Judicial discretionarity. Rational interpretation. Decision theory.

\section{SUMÁRIO}

1 Introdução. 2 Atividade interpretativa e intangível constitucional. 3 Apontamentos sobre os limites e alcances da interpretação constitucional. 4 Conclusão. 5 Referências. 


\section{INTRODUÇÃO}

Tendo em vista que o Brasil possui uma Constituição aberta em seus conceitos, prolixa em seus conteúdos e dotada de ampla pluralidade, é necessário que não somente os legisladores, mas também os juízes e tribunais, bem como os governantes, redobrem atenção em suas funções típicas. Nesse sentido é que o dever primordial da legislação se fixa em aperfeiçoar e trazer para o plano concreto os mandamentos e as orientações constitucionais. Do mesmo modo, a atribuição judicante vem pautada na Constituição, tendo como objetivo a aproximação da Justiça e a correção nos percursos da satisfação normativo-constitucional. O governo, no que lhe compete, faz frente a toda a realização das tarefas que a Constituição impõe, enquanto tem no Estado o destinatário de grande parcela das normas de direitos fundamentais.

Este é um quadro ideal, que serve de panorâmica à temática ora enfrentada, a qual se situa na questão da hermenêutica constitucional, visando a uma interpretação coerente por meio do exercício prático da jurisdição constitucional. O primeiro recorte delimitativo busca a compreensão e a realização de apontamentos sobre a atividade jurisdicional. Por essa razão o objetivo do artigo é apontar os problemas da jurisdição constitucional e apresentar o papel concretizador/realizador da interpretação da Constituição.

O problema que aqui se busca discutir situa-se na questão nem tão atual de saber se os juízes criam o Direito na atividade jurisdicional. E se esta atividade criativa concorre ou aprimora a legislação, tendo como objeto da problematização investigar qual a posição da Constituição em relação ao Direito.

As hipóteses aqui discutidas têm por premissa inicial que a jurisdição encontra limites no intangível constitucional como diferencial das cláusulas pétreas e que a legislação precisa ser respeitada. Se a Constituição ocupa o lugar central do ordenamento, então os direitos fundamentais são o norte da interpretação e da criação judicial do Direito. A partir de tal noção é que o texto objetivará inferir as primeiras ideias de uma - ou mais uma - teoria da decisão.

Metodologicamente de filiação hipotético-dedutiva, o texto busca construir as conjecturas mediante as hipóteses e pauta-se pela técnica da pesquisa bibliográfica predominantemente, sendo dividido em duas partes. Trata ele, primeiramente, da atividade interpretativa e do intangível constitucional e, em um segundo momento, de apontamentos sobre os limites e alcances da interpretação.

\section{ATIVIDADE INTERPRETATIVA E INTANGÍVEL CONSTITUCIONAL}

No contexto do pós-positivismo fica assente que o Direito, por si, não é suficiente para formatar respostas adequadas aos fins macros a que se destina. Ou seja, é possível afirmar que o Direito sozinho não alcança a pacificação social e não consegue subsidiar as relações individualizadas nos casos concretos. De um todo, com o apoio das normas gerais e abstratas é possível ao juiz alcançar em suas decisões as aproximações da Justiça, valendo-se da aplicação do Direito e, indissociavelmente, da interpretação.

Com base nas proposições de Kelsen (1998, p. 171-174), na Teoria Pura do Direito, o Direito encerra uma noção de completude e o juiz tem o dever de dar respostas ao caso concreto baseado nesse sistema fechado do Direito, composto de regras. O ordenamento jurídico fornece ao juiz a moldura para que ele possa trabalhar o Direito e fornecer a solução ao caso concreto, perquirindo, pela interpretação, o produto final do Direito, sem lhe acrescentar ou retirar elementos constitutivos. Dessa forma:

O positivismo, no qual se pode dizer que se fundamenta toda a teoria do ordenamento jurídico, descreve o direito como composto de regras em que se resolvem todos os conflitos dentro do próprio sistema normativo, cujos fundamentos não se abriam a questionamentos filosóficos ou mesmo políticos.

A teoria kelseniana foi o ápice e a que melhor expressou o pensamento jurídico positivo, consolidando, na Teoria Pura do Direito, a tentativa de apresentar respostas a todas as questões que lhe são relativas, dentro do sistema (MACHADO, 2011, p. 27).

Em que pesem as regras possam ser vistas alicerçadas em um modelo estático e assim classificadas por Hart (2001, p. 102) para efeitos da compreensão da sua obra $O$ Conceito de Direito, a interpretação é um elemento indissociável do alcance do objetivo da norma (mens legis). Com fundamento no uso da linguagem para dar o sentido jurídico, Hart (2001, p. 140-141) torna evidente, com sua teoria, a textura aberta que permeia a comunicação, podendo ser permitidos diversos significados ao texto legal. Nos casos mais simples é 
possível verificar que, de certo modo, o uso da interpretação pode levar ao certo ou ao errado, tendo em vista que a linha de incertezas é quase inexistente e que a regra de verificação é, praticamente, automática. A interpretação aparece para o Direito, tendo em vista a incapacidade de tudo se antecipar, isto é, os legisladores não detêm conhecimento de tudo o que o futuro pode trazer (HART, 2001, p. 141).

A textura aberta é um atributo que visa a driblar esta incapacidade prognóstica do ser humano, por meio da criação de padrões gerais pelo Legislativo, que dão à administração pública e ao Judiciário discricionariedade para moldar a decisão ao caso concreto, adaptando as regras às necessidades especiais (HART, 2001, p. 144). Neste ponto, surgem os casos difíceis, que são aqueles em que a generalidade da regra permite uma diversidade de interpretações, não sendo possível obter um silogismo a partir do uso da linguagem, em razão da textura aberta, demandando maior discricionariedade do juiz.

O poder de discricionariedade do juiz estaria pautado na própria aplicação de princípios e doutrinas para fundamentar as decisões. Diante da possibilidade de princípios contraditórios, a que evidencia a necessidade de discricionariedade, o juiz terá de escolher no sentido do que é melhor e não em qualquer ordem de prioridade, segundo Hart. Não existe um critério seguro que possa medir o peso dos princípios em cada caso, sendo necessário, portanto, a discricionariedade (FUGA, 2018, p. 321).

A discricionariedade da qual o juiz se vale para interpretar as normas e procurar dar solução ao caso concreto ganha corpo também com o aporte teórico fornecido por Dworkin (2002, p. 50-63). Quando Dworkin faz a análise do ordenamento, não só admite a inserção de pautas morais na forma de princípios, mas também tem neles o instrumento de excogitação pela melhor solução possível do caso concreto. Especialmente em casos difíceis, a discricionariedade judicial se potencializa, pois fica evidente que o Direito, por si, não consegue estabelecer uma solução adequada ou, muitas vezes, aproximada da necessidade real. Esclarece Dworkin (2002, p. 51-55), no entanto, que a discricionariedade pode ser forte, ocasião em que cria novas regras; ou pode ser fraca, no sentido de que suplementa e otimiza as regras já existentes, fazendo sua opção por este último modelo como o mais adequado. Para melhor elucidar a dicotomia das discricionariedades dworkinianas:

É no sentido forte da discricionariedade que se pode ter um alto grau de incertezas e de injustiças, exteriorizadas por lacunas, quando, na verdade, existe um dever legal do juiz de decidir. Esse alto grau de incertezas poderá levar a uma decisão indevida.

(...)

Nesse caminho, o juiz tem o dever jurídico de buscar a melhor justificação moral, partindo da análise dos princípios e das regras, entendidos como valores morais objetivos, que um homem razoável poderia interpretar de diferentes maneiras, fornecendo a esses casos difíceis critérios mais objetivos do que o mero recurso à discricionariedade em sentido forte, sem contudo retirar do juiz a discricionariedade em sentido fraco. De acordo com esse modelo, pode-se dizer que o juiz tem sempre a obrigação de buscar a resposta correta no direito preestabelecido. Portanto, não deve exercer o seu poder de forma a legislar (MACHADO, 2011, p. 38-39).

A digressão feita anteriormente, passando por Kelsen, Hart e Dworkin, serve como uma base teórico-dialética para a compreensão da atividade hermenêutica, passando pelos primados do positivismo e do pós-positivismo, a fim de mostrar qual seria a forma mais próxima de uma interpretação adequada. Por certo que a criação livre do Direito pode levar a efeitos mais negativos do que positivos, assim como uma aplicação fechada do ordenamento jurídico não alcança resultados diferentes.

Tratando com seriedade a separação das funções, não é dado ao Judiciário a atividade de legislar e a partir dessa premissa é que serão formadas as proposições acerca do limite da interpretação. Para isso, o objeto é estreitado na interpretação constitucional, ocasião em que se apresenta o intangível constitucional.

Dessa forma, diferentemente das cláusulas pétreas expressas no artigo 60 , §4으 da Constituição Federal de 1988, o intangível constitucional apresenta-se como uma proteção especial à potência da Constituição, resguardando não só o texto posto e a intenção do constituinte, mas garantindo a força contemporânea e a existência futura da Constituição.

É de se observar que as cláusulas pétreas são um constructo da Teoria Constitucional que se figura bem sedimentado, especialmente porque tem como fim coibir a modificação de determinadas normas constitucionais concretas e, da mesma forma, certos valores implícitos da Constituição (LOEWENSTEIN, 1979, p. 189). Pontos de relevância para a manutenção e existência do Estado de Direito Social tais como: forma federativa 
de desenho institucional, alternância periódica dos representantes do povo, independência e credibilidade das instituições do Estado e a garantia dos direitos fundamentais, são o núcleo material das cláusulas pétreas brasileiras, cuja proteção também se irradia sobre bases implícitas, por exemplo, no princípio da vedação ao retrocesso e na garantia do devido processo legal.

Essa proteção, no entanto, que se apresenta forte para conter a alteração material do texto constitucional, se desmancha quando é colocada como barreira diante da atividade de interpretação exercida pelo Judiciário. Nadja Machado Botelho defende que a mutação constitucional se sujeita ao regime das cláusulas pétreas, segue com lastro na concepção de que a dinâmica do processo de limitação à reforma aplica-se a tal espécie de decisão judicial, pois "o que não se pode é pretender, via mutação, aquilo que não se alcançaria nem por emenda" (BOTELHO, 2011, p. 40).

Basta, contudo, refletir que na Rcl 4335-AC, de 2007, julgada em 2014, se operou por via reflexa a mutação do artigo 52, X, da Constituição Federal de 1988, e, com isso, a atribuição de efeitos erga omnes e vinculantes às decisões em sede de recursos extraordinários não mais dependeria da edição de resolução por parte do Senado Federal, violando a separação dos poderes, no que tange ao sistema de freios e contrapesos. De forma semelhante, no HC 126.292, o STF mudou sua posição e passou a considerar possível a execução provisória da pena após o julgamento pela segunda instância, não mais necessitando do trânsito em julgado da decisão penal condenatória, violando o direito fundamental de liberdade, trazido no artigo 5o, LVII da Constituição Federal de 1988.

Em vista disso, é possível também localizar a posição do ativismo judicial, que "somente se justifica na defesa das minorias, firmando-se em uma função contramajoritária capaz de impulsionar a efetividade dos direitos fundamentais" (SCHERCH; ALVES, 2019, p. 83). Nessa ocasião, o juiz precisa ter um alinhamento jurídico que corrobore a mesma escolha política da Constituição, que o autorize a sair da posição de inércia para avançar sobre a função de governo e de criação legislativa apenas para garantir a eficácia e a existência de direitos fundamentais acessíveis a todas as categorias que compõem a sociedade.

O intangível constitucional se põe como um mecanismo de proteção contra a alteração informal dos sentidos da Constituição, ao manter intactos os objetivos constitucionais diante de decisões que tentam minar o conteúdo normativo e lhe negar efetividade.

Com o apoio das asserções Bayón (2000, p. 65-94) em seu artigo Direitos, Democracia e Constituição é possível obter uma ideia geral do envolvimento do intangível constitucional. Isso porque a primeira ideia que Bayón desenvolve trabalha com duas concepções: o "coto vedado" e o constitucionalismo. A expressão "coto vedado" foi cunhada por Valdés (1989, p. 631-650) para designar os direitos vinculados com a satisfação dos bens básicos, ou seja, que são condição necessária de qualquer plano de vida. Traduzida literalmente, significa "terreno proibido" e na sua significação jurídica é justamente um núcleo intocável de direitos básicos, que, dada a importância, não são objeto de modificação. Por óbvio, admitem aprimoramento ou expansão, inserindo-se na mesma ideia que se sedimenta a respeito da vedação ao retrocesso e, em paralelo, da concepção de cláusulas pétreas da doutrina constitucional.

O propósito de trazer o "coto vedado" para dentro da Constituição implica uma concepção diferenciada de constitucionalismo, trabalhando também com um procedimento democrático, razão pela qual a posição de Bayón (2000, p. 70) é pela defesa de um constitucionalismo fraco. Inevitavelmente, ao se falar em democracia, a discordância é um fator quase permanente nos procedimentos, bem por isso, são trabalhados os ideais de decisão da maioria e de decisão judicial (coletiva) na busca pela definição substancial desses direitos básicos. E essa é a ideia nuclear do texto.

Para efeitos deste trabalho, "constitucionalismo" é o movimento político, jurídico e social pautado pelo objetivo de criar um pensamento hegemônico segundo o qual todo Estado deve estar organizado com base em um documento fundante, chamado Constituição, cujo propósito essencial seria o de organizar o poder político, buscando garantir os direitos fundamentais e o caráter democrático de suas deliberações-(ARAUJO; NUNES JÚNIOR, 2016, p. 24). 
Bayón (2000, p. 70-75) vale-se em muito de Waldron, especialmente no artigo A Right-Based Critique of Constitutional Rights (1993, p. 18-51), pelo que se pode aqui fixar o marco teórico do trabalho e, já de início, assente em uma concordância com Waldron, a judicial review não se destaca perante o exercício parlamentar, razão pela qual se delineia a limitação da atividade hermenêutica de acordo com os parâmetros fornecidos pela lei.

Desse modo, em um constitucionalismo "forte", o limite real para o poder de decisão da maioria não são os direitos constitucionalizados, mas a decisão do órgão que exerce o controle judicial de constitucionalidade ao definir o limite e o alcance desses direitos (BAYÓN, 2000, p. 71).

Quanto à questão da decisão da maioria diante do controle judicial de constitucionalidade, admite Bayón (2000, p. 72) que "não se trata puramente de escolher entre um procedimento que tenha ou não limitações substanciais", mas que o ponto principal é que a regra da maioria vai bem em uma comunidade na qual os indivíduos que se reconhecem entre si como agentes morais de igual dignidade e que tanto a decisão da maioria como o controle judicial de constitucionalidade são falíveis.

Desta forma, para Bayón (2000, p. 76), tem-se "um sistema político no qual os direitos não seriam concebidos como um limite externo e prévio ao procedimento majoritário, mas como um produto gerado por seu próprio funcionamento". Diante disso, figura como condição necessária a participação, em pé de igualdade, nas tomadas de decisão públicas. Figurando, ainda, a constitucionalização da democracia como outra condição necessária, na medida em que "uma comunidade não deveria poder decidir por maioria deixar de decidir por maioria, e isso implica na autorrefutação da decisão democrática original, que deve ser contínua, sem autoanulação".

A partir da alegoria de Ulisses, Bayón (2000, p. 79) estabelece que "o dualismo democrático busca, através da idéia de pré-compromisso, uma profunda reconciliação entre a primazia constitucional e a regra de decisão pelas maiorias", mas não descarta a problemática da limitação individual como se coletiva fosse e a situação da Constituição rígida, principiológica, aberta, que precisaria ser enfrentada.

No que alcança a esfera do procedimentalismo, Bayón (2000, p. 80) entende que "todos os direitos deveriam ser o resultado de decisões comuns do legislador democrático", exceto os de caráter constitutivo ou de definição do próprio procedimento democrático. Razão pela qual as tomadas de decisão por maioria em uma democracia representativa exige, como condição de possibilidade, um conjunto de regras para o "constitutivo do soberano" tal qual afirma Hart. Como as discordâncias naturais das diferentes concepções do ideal de igualdade política são recorrentes no procedimento, as decisões têm de partilhar de um núcleo comum mínimo (intangível), que é a própria noção de democracia e de não afastar as pessoas das decisões, ou seja, não é admitido um processo de eliminação, mas é buscado um consenso, ao que parece, no sentido habermasiano.

Para o Bayón (2000, p. 84), o procedimento de determinação é inevitável quando as restrições substantivas são formuladas como princípios, mas se torna desnecessário se as restrições forem formuladas na forma de regras suficientemente precisas.

É possível, então, "um constitucionalismo que consista verdadeiramente na imposição substantiva de limites à regra da maioria, e não na limitação desta por quaisquer decisões coletivas que se utilizem de outros procedimentos suplementares" (BAYÓN, 2000, p. 84), não descartados os problemas do desacordo e da indeterminação de nossas próprias concepções sobre o conteúdo e limites das restrições substantivas, pois, na condição de regras, são o tudo ou nada de Dworkin, mas como princípios são imbuídas de vagueza e, muitas vezes, de uma alta carga de abstração que somente é suprida com a aplicação ao caso concreto.

Por essa razão Bayón (2000, p. 86), utilizando-se da ideia de Waldron (1993, p. 18-51), esclarece que quando as decisões "são tomadas de qualquer forma que não seja por maioria (não reforçada), o direito dos cidadãos à participação em pé de igualdade na tomada de decisões é violado". Nesse sentido, o procedimento democrático possui um valor intrínseco ao considerar que o valor moral do governo representativo se dá não por causa de sua qualidade, mas pelo número de cidadãos comuns que a respaldam e nenhum outro procedimento garante a mesma capacidade de reação para a maioria dos cidadãos diante de decisões de desaprovação.

Contrapondo isso ao valor instrumental do constitucionalismo, são reveladas situações como a de legisladores sob pressão (pela necessidade de se elegerem) e que os juízes seriam imunes a certos tipos de pressão, em virtude da posição institucional que têm. 
O tipo de resultado que se espera de uma certa regra de decisão coletiva, porém, depende de fatores contextuais, e que, portanto, se apenas o seu valor instrumental é levado em conta, diferentes regras de decisão são apropriadas para diferentes condições sociais. Enfatiza Bayón (2000, p. 88), nesse sentido, que "é fácil de encontrar muitos exemplos não só de freios às leis tendentes a erodir direitos básicos, mas também é intento de legisladores de promovê-los que resultarão abortados por decisões retrógradas de juízes constitucionais" e que "os juízes constitucionais tendem a adotar uma atitude de deferência ao legislativo sempre que a questão parece duvidosa", pelo que deveria ser adotado um constitucionalismo fraco.

A ideia conclusiva de Bayón (2000, p. 89) é que se se é partidário do ideal moral do "coto vedado", é preciso entender que um dos primordiais direitos é participar em igualdade de condições nas tomadas de decisão coletivas (dos juízes); então nessa zona de equilíbrio adequado entre valores procedimentais e substanciais é recomendável a adoção do desenho institucional que se pode chamar de "constitucionalismo fraco".

O pensamento central que se pretende, para afirmar o intangível constitucional, é que a interpretação se submete não somente à Constituição, mas também às suas finalidades e bases principiológicas, assim como é necessário respeitar a decisão popular - nos contextos histórico e social - que concebe determinado direito como fundamental e, por isso, intangível. Resultado disso é que a atividade interpretativa deve ser fraca para limitar-se a não reinventar o que a Constituição confere, ou seja, para não criar o direito geral e abstrato e, ao mesmo tempo, que não pode ser tão fraca a ponto de permitir que seja diminuído o catálogo de direitos fundamentais, impondo-se para garantir sua concretização.

\section{APONTAMENTOS SOBRE OS LIMITES E ALCANCES DA INTERPRETAÇÃO CONSTITUCIONAL}

Quando se trata da interpretação constitucional, entre uma vasta literatura sobre o tema, destacam-se a posição e a influência de Konrad Hesse na formação, especialmente, do método concretizador.

Informa Hesse (1983, p. 35-36), sobretudo, que a interpretação é um elemento necessário para que seja possível alcançar o significado e o conteúdo da Constituição. Assim, a interpretação é também um passo fundamental, tendo em vista o caráter aberto e amplo das expressões que a Constituição carrega em seu texto escrito. Ou seja, somente é possível extrair a normatividade das disposições constitucionais se realizada sua interpretação, porque a Constituição não tem pretensão de completude, mas de ser sempre atual ao tempo em que se encontra. Por isso:

Da perspectiva de Constituição no tempo, a Constituição só pode cumprir suas tarefas onde consiga, sob mudadas circunstâncias, preservar sua força normativa, isto é, onde consiga garantir sua continuidade sem prejuízo das transformações históricas, o que pressupõe a conservação de sua identidade. Partindo disso, nem a Constituição como um todo nem suas normas concretas podem ser concebidas como letra morta, como algo estático e rígido; precisamente sua continuidade pode chegar a depender da forma em que se encare a mudança (HESSE, 2009, p. 10).

Como a interpretação constitucional é uma atividade múltipla e, nesse sentido, Häberle (1997, p. 12-13) fala da sociedade aberta dos intérpretes da Constituição, no processo interpretativo "estão potencialmente vinculados todos os órgãos estatais, todas as potências públicas, todos os cidadãos e grupos, não sendo possível estabelecer-se um elenco cerrado ou fixado com numerus clausus de intérpretes da Constituição".

Ainda que a Constituição se dê num âmbito de interpretação horizontal, compreendendo tantos quantos possíveis intérpretes - e por isso é democrática - faz-se necessário - diante do monopólio da última palavra que é exercido pelo Tribunal Constitucional (aqui em suas variantes: Suprema Corte, Supremo Tribunal Federal, etc.) e tradicionalmente aceito - o alerta de Hesse (1983, p. 36), por isso "mesmo que o Tribunal seja competente para fixar o conteúdo da Constituição, com eficácia vinculante, não se encontra acima da Constituição à qual deve sua existência".

Como Hesse (1983, p. 37-38) assevera, para realizar a interpretação, por meio de regras tradicionais, que é preciso estabelecer, primeiramente, dois pontos de partida: (i) a vontade objetiva da norma (mens legis) e (ii) a vontade subjetiva do legislador (mens legislatoris), o que é possível analisando-se o texto, o processo de criação, suas conexões sistêmicas, seus antecedentes e o sentido (ratio) e finalidade (telos) da norma. Como o professor alemão deixa claro, no entanto, "as regras de interpretação tradicional fornecem uma solução/percepção parcial da questão, resolvendo os problemas de forma imperfeita" (HESSE, 1983, p. 42). 
A partir disso é que se pose falar em interpretação constitucional como concretização (Konkretisierung), isso porque "a interpretação constitucional tem caráter criativo: o conteúdo da norma constitucional somente é completo com sua interpretação e a atividade interpretativa é vinculada à norma" (HESSE, 1983, p. 43). Dessa forma, a concretização, necessariamente, pressupõe não somente a leitura e a investigação - tipicamente positivista - mas requer a compreensão do conteúdo da norma. E, para tanto, o intérprete passa pela leitura do problema concreto e da Teoria Constitucional para estabelecer uma pré-compreensão (HESSE, 1983, p. 44). Esta pré-compreensão é uma fase que permite analisar a norma desde certas expectativas e, a partir de uma ideia, formular um projeto de aproximação do texto com aquilo que a realidade o confronta. Ainda que o projeto tenha de passar por reformulações, correções e comprovações, ele permite a fixação de sentidos primários para a compreensão e a concretização a partir de um problema real.

Hesse (1983, p. 46-47) explica que o programa normativo é o texto da norma a se concretizar e deverá ser apreendido mediante a interpretação a que se refere sua significação vinculante para a solução de um problema. Para compreender corretamente o texto da norma são utilizados os métodos tradicionais: com a interpretação histórica, literal e sistemática, delimitando o espaço da norma; a interpretação teleológica, delimitando a direção da norma. No que toca ao âmbito normativo, pela interação da norma com a realidade, posto que não basta a compreensão textual sem trazê-la para os problemas concretos da vida, a interpretação visa a garantir a solução adequada, racional e controlável do problema, estabelecendo uma coordenação objetiva e relacionando várias normas e pontos de vista.

Com o objetivo de tornar a interpretação em uma atividade racional e coerente, Hesse (1983, p. 47-50) fixou princípios da interpretação constitucional, a serem observados para que possam orientar e canalizar o processo de relação, coordenação e valoração dos pontos de vista ou considerações que devem levar à solução do problema. Com isso, resta evidente que o intérprete não é livre para interpretar a Constituição de acordo com suas próprias concepções, sem que passe antes pela filtragem principiológica que orienta a atividade.

O princípio da unidade da Constituição tem por finalidade manter a interdependência dos seus elementos; segundo Hesse (1983, p. 48) as normas da Constituição são conjuntamente interpretadas, de modo a evitar as contradições de umas com as outras, evitando que as decisões básicas sobre a Constituição limitem-se de fora unilateral a aspectos parciais. Ou seja, na realização da interpretação é preciso levar em conta não somente a incidência da norma no caso concreto, mas também o impacto que o ponto de vista exarado tem sobre o conjunto normativo-constitucional.

Pelo princípio da concordância prática (HESSE, 1983, p. 48-49), a interpretação procura soluções que melhor se adéquem ao contexto do caso concreto, pretendendo o equilíbrio na proteção e garantia dos bens constitucionalmente contemplados. Por isso, ao contrário de uma ponderação de bens precipitada ou uma ponderação de valores abstrata, em caso de eventuais colisões em que um deva prevalecer sobre o outro, pela concordância prática é buscada a otimização, estabelecendo limites a ambos os bens para que alcancem uma eficácia otimizada.

Surge também, como informador da interpretação constitucional, o princípio da correção funcional, trazendo a ideia de que a Constituição regula, em certa medida, as condutas dos agentes das funções estatais, e, por isso, o órgão à qual é dada a função de interpretação deve manter-se a tal importância vinculado (HESSE, 1983, p. 49-50). Ou seja, pelo exercício da função de interpretação constitucional e da correção em eventuais desvios do iter constitucional, o órgão não pode usurpar a função legislativa ou executiva, mantendo assim a harmonia e a independência entre as funções do Estado, sob o pretexto de controle de constitucionalidade e de efetivação da Constituição.

Outro princípio é o da eficácia integradora, pelo qual as soluções dos problemas jurídico-constitucionais devem tencionar pontos de vista que promovam e mantenham a unidade política (HESSE, 1983, p. 50).

Por último, Hesse (1983, p. 50-51) cita o princípio da força normativa da Constituição, pelo qual as soluções dos problemas devem buscar a máxima eficácia e manter a Constituição atualizada. E é a partir da força normativa da Constituição que se pode extrair que "a Constituição não configura (...) apenas um ser, mas também um dever ser" (HESSE, 1991, p. 15), que condiciona os aspectos históricos e as possibilidades de utilização das informações da sociedade para a atualização da Constituição, objetivando sempre sua maior eficácia. 


\section{Debate}

Embora, no entanto, um diploma aberto e plural, a Constituição não dá ao intérprete a possibilidade de interpretar de forma ilimitada, figurando ela mesma - a Constituição escrita - no limite racional e estabilizador da interpretação, a fim de que os significados não se desviem no curso das modificações do texto constitucional (verfassungswandel) (HESSE, 1983, p. 55-57).

Vista a teoria de Konrad Hesse acerca da interpretação da Constituição é interessante e complementar a apresentação de linhas básicas da ponderação segundo o pensamento de Riccardo Guastini, a partir da percepção de Moreso (2005, p. 227-249) sobre o tema.

A incursão que Moreso (2005, p. 227-249) realiza traz importantes aportes sobre os problemas centrais enfrentados por Guastini em sua obra Distinguiendo: Estudios de teoría y metateoría del Derecho (2000). Precisamente, Guastini faz a distinções entre "disposição" e "norma", na qual a primeira é o texto dos documentos legislativos, é o objeto da atividade interpretativa, enquanto a última é o conteúdo desses textos. Assim, "a norma não é mais do que o resultado da atividade interpretativa" (MORESO, 2005, p. 228).

É interessante notar, como destaca Moreso $(2005$, p. 228), que a partir da teoria guastiniana, a disposição e a norma se relacionam, ao passo que uma disposição pode expressar uma pluralidade de normas e uma única norma pode ser expressa por várias disposições, assim como ocorre no ordenamento jurídico brasileiro, por exemplo, quando se tem a proteção integral das crianças e adolescentes espalhada em disposições constitucionais e legais.

Outra importante contribuição de Guastini, segundo Moreso (2005, p. 229), é que a norma não é pré-constituída, mas é o resultado da atividade hermenêutica, ou seja, para alcançar o significado da norma não basta apenas conhecê-la. A interpretação não é uma descoberta conteudística, mas consiste na proposta ou estipulação de significados ao texto. $\mathrm{E}$, nesse passo, Guastini defende uma posição cética da interpretação jurídica, na qual as afirmações produzidas não são produto do conhecimento, mas da vontade, do intérprete.

Como consequência dessa ideia de ceticismo quanto à atividade interpretativa é que se pode, em certa medida, desconfiar de certos significados que são atribuídos às normas, uma vez que haveria uma forte influência da vontade do intérprete. Por isso, questões relativas ao sopesamento ou ponderação precisam ser mais bem estruturadas dentro de um processo racional.

Segundo Guastini (MORESO, 2005, p. 230-231), tendo em vista que a contradição entre princípios difere das antinomias entre as normas legais, os critérios de solução do conflito (lex derogat inferior, lex posterior derogat tanto lex specialis derogat generali) não encontram satisfação na aplicabilidade; é necessário que se utilize da atribuição de uma hierarquia axiológica entre os princípios, pela qual se obtém uma relação de valor estabelecida pelo intérprete por meio de um juízo de valor. O resultado da avaliação é que um princípio (superior na hierarquia de valor) desloca o outro (ou outros) e é aplicável; como a hierarquia não se estabelece em abstrato, mas no caso concreto, Guastini (2000, p. 171) a denomina "hierarquia móvel", ou seja, "qualquer solução para o conflito é válida apenas para o caso específico e, portanto, a solução do mesmo conflito em casos futuros é imprevisível".

Enquanto as regras são estáticas, na colisão entre princípios, estes podem assumir diferentes pesos para preceder um ao outro no caso concreto. Essa espécie de precedência se dá pela ponderação e como os pesos são postos pelo intérprete, Alexy (2011) desenvolveu uma regra que contempla o maior número de condições relevantes para sopesar os princípios.

Diante dos estudos de Guastini (2000) sobre a ponderação, Moreso (2005, p. 249) destaca que o subjetivismo radical não encontra liberdade para infirmar qualquer hierarquização principiológica, tendo em vista que há diferentes níveis de moralidade - o nível intuitivo e o nível crítico - por meio dos quais é possível considerar e delimitar as propriedades mais relevantes no caso concreto para que se possa alcançar o objetivo; especialmente pelo nível crítico de moralidade, posto que fornece uma melhor análise da situação-problema, considerando o caso concreto como uma espécie de instância de uma objeção geral, ainda que em estágio de idealização.

A mobilidade das hierarquias, ainda que permeie a incerteza quanto à aplicação dos princípios em conflito, dado que o intérprete pode Ihe atribuir maior ou menor importância, ainda trabalha com hierarquizações ideais e, mesmo assim, não serve a converter a ponderação em um aparato subsuntivo (MORESO, 2005, p. 249). 
A racionalidade subsuntiva, conforme Moreso (2005, p. 249), é o que justifica a decisão; do ponto de vista subjetivo, nem sempre o intérprete está apto ou interessado em justificar suas decisões, porém, na medida em que consegue isolar um conjunto de propriedades relevantes, pode oferecer soluções para todos os casos, embora essas soluções possam ser questionadas quanto à adequação dos critérios pelos quais são selecionadas as propriedades relevantes.

Feitos estes apontamentos sobre a interpretação constitucional e a ponderação de princípios, cabe ainda uma última investigação a respeito da criação do Direito por meio da atividade interpretativa exercida pelos juízes.

Segundo a doutrina tradicional os juízes, dentro de sua competência, têm a obrigação de resolver todos os casos que lhes são submetidos, aplicando o Direito a casos particulares; as decisões dos juízes devem ser fundamentadas em normas jurídicas, portanto positivistas; e, em casos muito especiais, os juízes criam normas gerais. A partir dessas três teorias, Bulygin $(2005$, p. 7) traz importantes prospecções acerca da criatividade dos juízes.

Por certo que na criação de normas gerais a atividade é naturalmente atribuída ao poder Legislativo, restando ao poder Judiciário a atividade de sindicar a legalidade e a constitucionalidade. Pode-se dizer que na sentença o juiz cria o direito inter partes, como um produto final da criação normativa (KELSEN, 1998, p. 249).

Assim, as teorias que consideram o Direito completo e negam as lacunas, razão pela qual pode haver discricionariedade do juiz, ante o dever de resolver as questões por meio do que existe positivado; também há teorias que consideram que ainda que hajam lacunas, isso não impede os juízes de resolver todos os casos mediante a aplicação de normas gerais preexistentes e aqui não há discricionariedade do juiz, que tem de buscar nas fontes do Direito a solução ao caso que aprecia; e existem ainda teorias que sustentam a existência ou não de lacunas como uma questão empírica e, portanto, acidental ou causal - contingencial; aqui há discricionariedade do juiz, que se obriga somente à sentença (BULYGIN, 2005, p. 14-15). Também é certo que diante de casos difíceis o juiz se vale da pauta dos princípios para alcançar a solução mais próxima do adequado ao caso concreto (DWORKIN, 2002).

Acerca da discricionariedade do juiz para atuar no caso concreto, Bulygin (2005, p. 17-24) faz o apontamento da teoria de Fernando Atria, na qual: se, diante de normas gerais aplicáveis aos casos gerais o juiz justifica sua decisão no caso individual, então na ausência de normas gerais aplicáveis aos casos gerais, o juiz cria a norma geral para solucioná-lo; portanto, na ausência da norma geral, pode o juiz, discrionariamente, resolver o caso concreto, mas se compromete a adotar a mesma postura em todos os casos iguais, figurando nisso a "única resposta correta":

O que Atria chama de "a única resposta correta" não é mais do que um certo consenso sobre a solução que corresponde ao caso genérico para justificar a decisão no caso individual (...). Mas não há nada que force o juiz a adotar uma certa solução: tanto a condenação do réu quanto a rejeição da reivindicação requerem a criação de uma regra geral sem a qual a decisão do juiz não seria justificada, isto é, seria arbitrária (BULYGIN, 2005, p. 24).

Para se falar em uma criação judicial do Direito, segundo Bulygin (2005, p. 24-25), é preciso ter em consideração que a atividade jurisdicional não se limita à aplicação da norma ao caso concreto ou à criação subsuntiva do Direito; pois, se assim não fosse, não existiriam as decisões das Cortes Superiores e dos Tribunais locais, bem como o juiz de Primeiro Grau não poderia criar normas gerais ao se deparar com lacunas ou contradições normativas ou ainda lacunas axiológicas; porém a criação judicial difere da legislativa, pela vinculação geral desta última, enquanto aquela primeira gera um precedente e encaminha-se, por adesão, a uma uniformização jurisprudencial.

Por essa razão, no âmbito em que se opera a discricionariedade judicial como um atributo necessário da decisão judicial que permite a flexibilização da regra para a solução de um caso concreto, o Judiciário atua como agente de concretização dos direitos e não como um legislador positivo:

Quando se fala em flexibilizar a regra, é no sentido de dar-lhe efetividade diante de uma situação limite, um exercício exegético-funcional e não uma alteração do seu sentido original. Nesse âmbito, quando não há uma solução a se declarar, mas é necessário ao juiz valer-se de sua criatividade para buscar, dentro do ordenamento, a melhor solução possível (SCHERCH; ALVES, 2019, p. 85). 
Notadamente, as asserções acerca dos limites da criatividade judicial se encontram com aspectos filosóficos, importa dizer, não apenas em busca da (re)significação de postulados normativos, mas na compreensão do funcionamento dos sistemas, ou, simplesmente, entender as regras do jogo. É aqui que ganha importância a ideia de um giro linguístico-pragmático - porque trabalha com a linguagem e com a superação do esquema sujeito-objeto - pois:

É dessa forma que a significação só será possível a partir de um adestrar-se à forma como comumente é utilizada a linguagem em determinada coletividade. Aprender a jogar em observância às regras firmadas no meio social (leia-se: usar a linguagem), é o que vai permitir dar sentido e, portanto, conhecer o mundo pela linguagem (ALVES; OLIVEIRA, 2017, p. 144).

É daí que deriva a importância de conhecer métodos e procedimentos para se ter alguma teoria da decisão judicial, que enfrente pressupostos fáticos, normativos, culturais e também concepções do próprio indivíduo:

$\mathrm{Na}$ era das Constituições compromissórias e sociais (e dirigentes), enfim, em pleno pós-positivismo, uma hermenêutica jurídica capaz e intermediar a tensão inexorável entre o texto e o sentido do texto não pode continuar a ser entendida como uma teoria ornamental do Direito, que sirva tão somente para colocar "capas de sentido" aos textos jurídicos. No interior da virtuosidade do círculo hermenêutico, o compreender não ocorre por dedução. Consequentemente, o método (procedimento discursivo) sempre chega tarde, porque pressupõe saberes teóricos separados da "realidade". Antes de argumentar, o intérprete já compreendeu (STRECK, 2016, p. 192-193).

Decorre, dessas pré-compreensões do intérprete a necessidade de entender que a criação judicial firma-se em torno do movimento dinâmico da teoria e da realidade, respeitando as regras do jogo, no caso, a compreensão da Constituição.

\section{CONCLUSÃO}

A interpretação das normas representa uma importante fase para a exteriorização dos efeitos do Direito. É, precisamente, a passagem do formal para o material, não se resumindo à subsunção das regras aos fatos concretos que se enquadram em suas hipóteses. Diante da realidade, é perceptível que as normas gerais e abstratas não alcançam com exatidão as situações a que se propõem regulamentar e orientar.

A possível solução para o problema das lacunas reside na interpretação, todavia esta atividade precisa ser exercida a partir de uma organização e de limites, razão pela qual são estabelecidos os métodos. Com métodos é possível extrair o potencial da norma em sua concretização, trabalhando com os casos mais difíceis e, por vezes, de solução inimaginável.

A partir da interpretação é possível falar na criação da solução ao caso concreto, sem necessariamente implicar na criação do Direito - ou de um novo Direito. É importante observar o critério de criação controlável, posto que a Constituição se revela acima da interpretação e, por conseguinte, da vontade dos intérpretes.

Pela ideia de força normativa da Constituição e também pela proposta concretizadora, a partir dos conceitos de Hesse, é possível encontrar não somente os limites, mas os alcances da interpretação das normas, que devem ser conjugadas com a realização das tarefas que a Constituição impõe. Assim, um dos limites da interpretação é a própria Constituição, enquanto, pelo seu texto, leva o intérprete a criar aquilo que é permitido, contudo sem permitir a criação de normas propriamente ditas. $O$ intérprete trabalha com os sentidos das disposições já existentes, ocasião em que não pode emprestar palavras à Constituição sem levar em conta a realidade, a finalidade e a historicidade da norma que pretende ter como solução ao caso concreto, aparecendo também como limite da interpretação o intangível constitucional.

Nesse sentido, as expressões abertas e plurais devem ser interpretadas visando a uma evolução do pensamento jurídico e da norma constitucional, não para justificar a vontade e a escolha do intérprete.

No campo da aplicação dos princípios, é de se ter que os princípios sempre coexistem e se aplicam ao caso concreto de forma concomitante. A problemática encerra-se na atribuição de valores ou pesos, que podem tender a uma opção do intérprete e por isso, o critério mais racional e coerente é buscar a solução 
por meio da extração da maior eficácia da norma constitucional, adotando uma técnica que não privilegie o subjetivismo, mas a otimização dos resultados que podem ser obtidos com a atividade interpretacional e aqui talvez resida o ponto em comum entre Hesse, Dworkin e Moreso de acordo com os textos analisados.

Há uma criação judicial do Direito, como revela Bulygin, quando é feita a análise das decisões dos Tribunais e também em casos difíceis, não havendo dúvidas de que essa atividade interpretativa e criativa surge como a solução a inúmeros problemas ainda pendentes de regramento específico. Ocorre que, se pensado a fundo, os juízes não estão a criar novos direitos, mas geralmente acabam, pela via da interpretação, estendendo ou reduzindo direitos preexistentes, pois, na maioria das vezes, o caso chega ao Judiciário a partir de uma norma geral e abstrata preexistente. Embora a criação judicial do Direito aparente ser benéfica, pode atentar contra a segurança jurídica e, a depender do caso concreto, não fornecer um padrão de racionalidade para que a decisão seja utilizada como parâmetro informativo de orientação jurisprudencial.

Guardadas as diferenças entre os pontos de vista aqui apresentados, é unívoca a ideia de que a interpretação é um atributo necessário da atividade jurisdicional, assim como o juiz precisa adaptar a norma geral melhor aplicável ao caso concreto, dada à impossibilidade de antecipar todas as situações sociais para o campo jurídico. $O$ desafio de colocar limites ou parâmetros à discricionariedade do juiz em atividade criativa ainda persiste, justificando maiores pesquisas a respeito de uma teoria judicial, mesmo que existam outros trabalhos nesse sentido.

A legislação ainda é um parâmetro para a formação dos juízos interpretativos, por isso, ainda que a busca pela maior eficácia constitucional - e dos direitos fundamentais - seja norteadora, somente é possível pensar uma teoria da decisão com a presença de critérios racionais, coerentes e relevantes, que considerem o maior número possível de propriedades da norma e de sua aplicação ao caso concreto, numa marcha evolutiva.

\section{REFERÊNCIAS}

ALEXY, Robert. Teoria dos direitos fundamentais. Tradução Virgílio Afonso da Silva. 2. ed. São Paulo: Malheiros, 2011.

ARAUJO, Luiz Alberto David; NUNES JÚNIOR, Vidal Serrano. Curso de direito constitucional. 20. ed. São Paulo: Editora Verbatim, 2016.

ALVES, Fernando de Brito; OLIVEIRA, Guilherme Fonseca de. Entre o esquema sujeito-objeto e o esquema sujeito-sujeito: considerações sobre um novo paradigma. Revista de Estudos Constitucionais, Hermenêutica e Teoria do Direito, São Leopoldo: Unisinos - Universidade do Vale do Rio dos Sinos, v. 9, n. 2, p. 136-150, 14 nov. 2017. http://dx.doi.org/10.4013/rechtd.2017.92.05. BAYÓN, Juan Carlos. Derechos, democracia y constitución. In: LAPORTA, Francisco. Constitución: problemas filosóficos. Madrid: Centro de Estudios Políticos y Constitucionales, 2000.

BOTELHO, Nadja Machado. Mutação constitucional: a Constituição viva de 1988. Rio de Janeiro: Lumen Juris Editora, 2011.

BULYGIN, Eugenio. Los jueces ¿crean derecho? Isonomía: Revista de Teoría y Filosofía del Derecho, n. 18, abr. 2003. Alicante: Biblioteca Virtual Miguel de Cervantes, 2005.

DWORKIN, Ronald. Levando os direitos a sério. Tradução e notas Nelson Boeira. São Paulo: Martins Fontes, 2002.

FUGA, Bruno Augusto Sampaio. Hart. Análise da necessária discussão sobre a discricionariedade judicial. In: BANNWART JÚNIOR, Clodomiro José; FUGA, Bruno Augusto Sampaio (org.). Filosofia do direito. 2. ed. Londrina: Thoth, 2018. p. 317-333. Cap. 23.

GUASTINI, Riccardo. Distinguiendo: Estudios de teoría y metateoría del Derecho. Trad. castellana Jordi Ferrer. Barcelona: Gedisa, 2000.

HÄBERLE, Peter. Hermenêutica constitucional - a sociedade aberta dos intérpretes da constituição: contribuição para a interpretação pluralista e "procedimental" da Constituição. Tradução Gilmar Ferreira Mendes. Porto Alegre: Sergio Antonio Fabris Editor, 1997.

HART, Herbert Lionel Adolphus. O Conceito de Direito. 3. ed. Tradução A. Ribeiro Mendes. Lisboa: Gulbenkian, 2001.

HESSE, Konrad. A força normativa da constituição. Tradução Gilmar Ferreira Mendes. Porto Alegre: Sergio Antonio Fabris Editor, 1991.

HESSE, Konrad. Escritos de derecho constitucional. Introducción y traducción Pedro Cruz Villalón. Madrid: Centro de Estudios Constitucionales, 1983.

HESSE, Konrad. Temas fundamentais do Direito Constitucional. Textos selecionados e traduzidos por Carlos dos Santos Almeida, Gilmar Ferreira Mendes e Inocêncio Mártires Coelho. São Paulo: Saraiva, 2009.

KELSEN, Hans. Teoria Pura do Direito. Tradução João Baptista Machado. 6. ed. São Paulo: Martins Fontes, 1998. 
LOEWENSTEIN, Karl. Teoría de la constituición. 2. ed. Traducción Eduardo Espin. Barcelona: Editora Ariel, 1979.

MACHADO, Edinilson Donisete. Ativismo judicial: limites institucionais democráticos e constitucionais. 1. ed. São Paulo: Letras Jurídicas, 2011.

MORESO, José Juan. Guastini sobre la ponderación. Isonomía: Revista de Teoría y Filosofía del Derecho, Alicante: Biblioteca Virtual Miguel de Cervantes, n. 17, oct. 2005.

SCHERCH, Vinícius Alves; ALVES, Fernando de Brito. Discricionariedade judicial ou juízes legisladores: anotações sobre o limite e o alcance da atividade interpretacional dos juízes por meio de uma concepção coerente da discricionariedade. Revista Brasileira de Teoria Constitucional, [S.I.], v. 4, n. 2, p. 66-87, 8 fev. 2019. Conselho Nacional de Pesquisa e Pós-Graduação em Direito - Conpedi. http://dx.doi.org/10.26668/indexlawjournals/2525-961x/2018.v4i2.4819.

STRECK, Lenio Luiz. Hermenêutica, analítica e argumentação. In: CAMBI, Eduardo Augusto Salomão; MAGRAF, Alencar Frederico (org.). Direito e justiça: estudos em homenagem a Gilberto Giacoia. Curitiba: Ministério Público, 2016.

VALDÉS, Ernesto Garzón. Algo más acerca del "coto vedado". Doxa. Cuadernos de Filosofía del Derecho, Alicante: Universidad de Alicante Servicio de Publicaciones n. 6, p. 209-213, 1989. http://dx.doi.org/10.14198/doxa1989.6.12.

WALDRON, Jeremy. A Right-Based Critique of Constitutional Rights. Oxford Journal of Legal Studies, Oxford: Oxford University Press (OUP), v. 13, n. 1, p. 18-51, 1993. http://dx.doi.org/10.1093/ojls/13.1.18. 